\section{PENELITIAN KANDUNGAN LOGAM BERBAIIAYA PADA JERIGEN POLYOLEFIN DENGAN METODE ANALISA KUALITATIF}

Oleh : Kusumo Retno Winahyu, Sri Budiasih, Suparti

\section{ABSTRAC'T}

The Research of the contain of dangerous metal in Poly Olefin jerrycan detect the posible of dangerous metals like Mercury, Plumbum, Cupper and rsenic that be containied in jerrycan Poly Olefin. For this purpose it is used juades keep in 10 red and blue jerrycans Poly Olefins wich have capacity 20 1. ine nethod of examination by Volumetri Analysis. The results of the research ove that jerrycan Poly Olefins do not contain of dangerous metals like Merrry, Plumbum, Cupper and Arsenic.

\section{INTISARI}

Penelitian kandungan logam berbahaya pada jerigen Polyolefin memanyai tujuan untuk mendeteksi kemungkinan adanya logam-logam berbahaya, rupa $\mathrm{Hg}, \mathrm{Pb}, \mathrm{Cu}$ dan As pada jerigen Polyolefin. Penclitian ini menggunakan ntoh uji aquades yang disimpan pada jerigen Polyolefin warna merah dan biru hanyak 10 buah dengan kapasitas 20 liter. Metode pengujian dilakukan dean cara analisa Volumetri (uji kualitatif). Hasil pengujian menunjukkan bahtidak terdeteksi kandungan logam berbahaya pada jerigen Polyolefin.

\section{PENDAIIULUAN}

Jerigen Polyolefin mempunyai fungsi yang cukup besar, bisa digunakan htuk mengangkut hermacam-macam cairan antara lain minyak tanah, minyak lapa, bensin serta air minum (aquades).

Schubungan dengan fungsi jerigen yang digunakan sebagai pengemas air inum, perlu mendapat perhatian yang serius akan keamanan pakai jerigen tercbut. Adanya zat-zat penyusun bahan baku plastik untuk membuat produk erigen yang kemungkinan digunakan secara berlebihan, dapat bermigrasi pada airan yang dikemas, dalam hal ini adalah air minum aquades.

Majalah Barang Kulit, Karet dan Plastik
Menurut Standar dari Departemen Kesehatan, SII. 71-75 air minum tidak bolch berbau, berasa serta tidak holch mengandung logam $\mathrm{Cu}, \mathrm{Hg}, \mathrm{Pb}$ dan As. isasi.

Polyolefin termasuk Thermoplastik hasil Polimerisasi atau Copolimer-

Jerigen plastik yang ada di pasaran terdiri dari bermacam-macam kualitas sehingga sangat menyulitkan konsumen untuk memilih jerigen yang bermutu baik dan tidak mengganggu keschatan. Banyaknya kualitas yang beragam kadang-kadang merugikan konsumen, hal ini kemungkinan discbabkan oleh pemakaian reklim dari bahan yang mutunya rendah schingga berakibat buruk bagi kesehatan konsumen, hal ini dimungkinkan adanya migrasi zat-zat maupun logam-logam berbahaya dari bahan plastik terhadap air minum yang dikemas (6).

Jerigen plastik dibuat dengan proses cetak tiup (blow molding), dimana proses tersebut merupakan pengembangan dari proses cetak injeksi (injection molding) serta extrusion molding. Kemajuan pertumbuhan proses cetak tiup barang-barang plastik, karena kecepatan pertumbuhan Industri barang-barang plastik yang begitu pesat. Bahan-bahan yang digunakan untuk proses pembuatan cetak tiup pada umumnya plastik golongan thermoplas antara lain : Polyethylene, Polystirene, Polypropilene, Polyvinylchlorida, Polycarbonat, Polyasetat dan lain-lainnya (3).

Bahan baku jerigen pada umumnya menggunakan bahan Polyolefin, sedangkan botol-botol pengemas dibuat dari bahan Polyvinylchlorida, PolyethyIenc. Untuk memperoleh sifat produk yang dikehendaki, bahan baku tersebut ditambah dengan bahan-bahan pembantu yang berupa filler, anti oksidant, plasticizer, softener dan lain-lain. Macam dan jumlah bahan baku serta bahan pembantu yang dikchendaki tergantung dari jenis dan sifat produk yang dikehendaki. Pada umumnya untuk membuat barang-barang dengan melalui proses cetak tiup digunakan kompon. Kompon merupakan campuran bahan baku serta bahan pembantu.

Untuk memberikan daya tarik produk-produk yang dihasilkan perlu ditambahkan zat warna, untuk jerigen dengan kapasitas 20 liter warna yang umum digunakan adalah putih, biru serta merah. Sedangkan untuk jerigen berkapasitas 10 sampai dengan 5 liter atau lebih kecil dijumpai warna-warna bervariasi, bahkan sering dijumpai warna-warna yang cenderung kusam. Hal ini discbabkan karena penggunaan reklim yang berlebihan. Berbeda dengan jerigen yang berkapasitas 20 liter, pada umumnya menggunakan bahan baku resin murni sehingga warna yang dihasilkan nampak terang.

Vol. IX No. 17 Tahun 1993/1994 
han pewarna yang ditambahkan mempunyai persyaratan sebagai berikut : an terhadap suhu tinggi $\left(280^{\circ} \mathrm{C}\right)$, serta kemampuan larut yang baik. Pewarna g bisa digunakan untuk Polyolefin adalah pigmen organik. Untuk warna ih menggunakan Titanium dioksida, Zink oksida, Antimoni oksida. Warna am menggunakan channel black, furnance black. Warna merah menggunakan i oksida. Warna kuning menggunakan Chrom yellow. Warna orange menghakan Chrom orang. Warna hijau menggunakan Phtalo cyanine green. langkan warna biru menggunakan Phtalo cyanine blue (5).

Pada prinsipnya jerigen dibuat dengan cara cetak tiup, yang prosesnya diri dari 3 (tiga) tahap yaitu : Tahap pelelchan, dimana pada tahap ini komn mengalami pelelchan (lunak). Kemudian kompon leleh tersebut didorong uar oleh suatu ulir menuju "die". Kompon Icleh yang keluar melalui "dic", diut dengan istilah "Parison", sclanjutnya parison masuk dalam tahap penakan. Setelah tahap pencetakan mengalamai proses curing, produk yang diak siap dikeluarkan dari cetakan. Tahap terakhir adalah tahap penyelesaian. lam tahap ini dilakukan penyempurnaan terhadap produk dan produk siap asarkan (3).

Di pasaran banyak sekali dijumpai ancka jerigen dengan berbagai ukuran upun warna. Warna merah, putih serta biru. Disamping warna-warna terut ada juga warna yang kenampakannya kusam, banyak sckali dijumpai pada gen dengan kapasitas kurang dari 20 liter. Hat ini disebabkan karena pemaan riklim untuk menekan harga jual. Sesungguhnya pemakaian jerigen untuk minum ada specifikasi khusus yaitu adanya simbol pada jerigen berupa O". Tetapi pada praktcknya jarang sckali dijumpai simbol $\mathrm{H}_{2} \mathrm{O}$ pada produk gen yang cukup melimpah di pasaran. Padahal konsumen banyak yang menfaatkan jerigen plastik Polyolefin sebagai penampung air minum. Hal ini lu mendapat perhatian agar keschatan konsumen tetap terlindungi. Schingperlu dilakukan penelitian kemungkinan adanya kandungan logam berbahapada jerigen Polyolefin dengan metode analisa kualitatif.

\section{MATERI DAN METODE}

\section{Materi Penelitian}

\subsection{Bahan}

\author{
a. Aquades \\ b. Reagen $\mathrm{KJ}, \mathrm{K}_{2} \mathrm{CrO}_{4}, \mathrm{H}_{2} \mathrm{SO}_{4}, \mathrm{NH}_{4} \mathrm{OH}, \mathrm{Ag} \mathrm{NO} 3, \mathrm{Cu} \mathrm{SO} 4, \mathrm{NaOH}$
}

Majalah Barang Kulit, Karet dan Plastik

\subsection{Alat}

Erlenmeyer, pipet, tabung reaksi, jerigen dan kompor

\section{Metode Penelitian}

\subsection{Persiapan Contoh Uji}

Aquades dididihkan sampai mencapai suhu $100^{\circ} \mathrm{C}$, kemudian dimasukkan kedalam jerigen yang berkapasitas 20 liter warna merah dan putih. Kemudian suhu aquades diturunkan menjadi $80^{\circ} \mathrm{C}$ dan dimasukkan kedalam 2 buah jerigen warna merah dan putih begitu seterusnya untuk suhu aquades $60^{\circ} \mathrm{C}, 40^{\circ} \mathrm{C}$ dan suhu kamar. Setelah jerigen Polyolefin diisi dengan aquades dari bermacam-macam suhu disimpan selama 24 jam. Untuk selanjutnya dianalisa dengan metode analisa volumetri.

\section{Pelaksanaan Pengujian}

Contoh uji berupa aquades yang dikemas dalam jerigen Polyolefin dituang kedalam tabung reaksi scbanyak $\pm 5 \mathrm{ml}$. Tambahkan beberapa tetes reagen yang spesifik untuk penunjukan adanya logam-logam berbahaya $(\mathrm{Cu}$, $\mathrm{HG}, \mathrm{Pb}$ dan $\mathrm{As}$ ). Untuk penunjukan logam $\mathrm{Cu}$ digunakan reagensia $\mathrm{NaOH}$ serta reagensia $\mathrm{NH}_{4} \mathrm{OH}$, untuk penunjukan logam $\mathrm{Hg}$ digunakan reagensia $\mathrm{KI}$ serta reagensia $\mathrm{K}_{2} \mathrm{CrO}_{4}$, untuk penunjukan logam As digunakan reagensia $\mathrm{AgNoO} 3$ dan reagensia $\mathrm{CuSO}_{4}$. Apabila terjadi endapan dengan warna yang spesifik menunjukan adanya kandungan logam yang terlarut dalam contoh uji.

\section{HASIL, PENELITIAN DAN PEMBAILSAN}

Dari hasil uji dengan menggunakan metode analisa volumetri (cara kualitatif), ternyata contoh uji aquades menunjukan hasil negatif, hal ini herarti bahwa didalam larutan aquades tidak dijumpai adanya logam berbahaya $(\mathrm{Cu}$, $\mathrm{HG}, \mathrm{Pb}$ dan $\mathrm{As}$ ). Hal ini menunjukan bahwa bahan baku plastik yang digunakan terbuat dari resin murni sehingga sangat kecil kemungkinan zat penyusun plastik dapat bermigrasi kedalam air yang dikemas.

Vol. IX No. 17 Tahun 1993/1994 


\section{KESIMPULAN}

Tidak terdeteksi adanya logam-logam berbahaya didalam jerigen PolyoIefin berkapasitas 20 liter, sesuai metode analisa volumetri (cara kualitatif).

\section{DAFTAR PUSTAKA}

1. Balai Penclitian Kimia Surabaya (1997), "Penuntun cara-cara analisa kimia air".

2. Elizabeth Larmond (1924), "Methods for Sensory Evaluations of Food", Food research, Central Experimental Farm, Ottawa.

3. Edwin G. Fisher, "Blow Molding Plastics", London Iliffe Baolis.

4. Herman Busser, "Ringkasan Analisa Jenis", BPK Bogor.

5. Mokhtar Ahmed (1979), "Cloring of Plastics", Van Nostrand Reinhold Company.

6. Susilowati dkk (1984), "Proses dan Family Tree Pembuatan barang-barang plastik", Balai Besar Penclitian dan Pengembangan Industri Barang Kulit, Karet dan Plastik Yogyakarta. 